\title{
Narrando a diáspora: deslocamentos e fluxos populacionais de bolivianos para o Brasil
}

\author{
Narrating the diaspora: displacements and \\ population flows of bolivians to Brazil
}

\author{
Vanessa Generoso Paes
}

Mestre em História Social pela USP e pesquisadora no Núcleo de Estudo em História Oral - USP e Diversitas/USP* vanessa.narracao@gmail.com

\section{Resumo}

Este artigo propõe uma análise sobre o deslocamento dos bolivianos para o Brasil a partir das histórias de vida dos sujeitos envolvidos em tais tramas históricas. Por este trabalho ser desdobramento da dissertação de mestrado, que nos permitiu uma imersão profunda no cotidiano de imigrantes desde os seus lugares de origem aos de destino, em busca de saberes qualificados pelas experiências dos que sazonalmente se deslocam como andorinhas entre os altiplanos dos Andes e a cidade de São Paulo. No referido trabalho, foram abordados os processos históricos envolvendo um clã familiar boliviano (os Patzi), sua rede social e afetiva. Duas entrevistas foram realizadas com uma família transnacional que vive na Bolívia e no Brasil. Uma entrevista permitiu que visualizássemos a formação de uma rede de trabalhadores e donos de oficinas de costura em São Paulo. Duas nos levaram a uma rede de feirantes que trabalham na Praça Kantuta, em São Paulo, uma rede de intelectuais bolivianos e outra de retornados. As entrevistas foram analisadas a partir de um diálogo entre as próprias narrativas e suas linhas de argumentação temática. A partir dessa perspectiva, foi possível constatar que as identidades são concebidas como heterogêneas, em processo, em trânsito, articuladas por zonas de contato e trocas culturais. As memórias dos narradores revelam campos de disputas, manifestam a diversidade, as ambiguidades das reminiscências e de seus esquecimentos. As lembranças passaram por reapropriações culturais no processo de deslocamentos continentais e transfronteiriços no cenário latino-americano.

Palavras chaves: Narrativa, diáspora, deslocamento populacional, bolivianos.

\section{Abstract}

This article proposes an analysis about the displacement of bolivians to Brazil from the life history of the people involved in such historical wefts. Fort he reason that this article is a deployment of the master thesis, that allowed a deep immersion in the daily life of the immigrants from their places of origin to destination, seeking qualified knowledge by the experience of the people that move therseves like sawallows among the Andes's highlands ans the city of São Paulo. In the mentioned thesis were addressed the historical process involving a bolivian family clan (the Patzi) and their social and affective network. Two interviews were made with a transnational family that lives in Bolivia and Brazil. One interview allowed the shapping of a nework ok employees and owners of the sewing workshops in São Paulo. Two interviews led us to a network of stallholders that Works in Kantuta's Square in São Paulo, a network of bolivians intelectuals, and, another of returned. The interviews were analized from a dialogue between the narratives themselves and their lines of thematic argumentation. It is clear, from this perspective, that the indentities are conceived as heterogeneous, in process, in traffic, articulated by zones of contact and cultural exchanges. The narrator's memories shows disputes, manifest the diversity, the ambiguities of the reminiscences and their forgetfulness. The remembrances go though cultural reapropriations in the process of borders and continental displacements in latin american scene.

Key-words: Narrative, diáspora, populational displacements, bolivians. 


\section{Apresentação}

Este artigo analisa, por meio das histórias de vida dos bolivianos ${ }^{1}$, o trânsito e o processo diaspórico de bolivianos perante os deslocamentos latino-americanos que ocorrem entre a Bolívia e o Brasil. Utilizamos os procedimentos da história oral de vida (HOLANDA; MEIHY, 2007) para a constituição das narrativas. Para compor o corpus documental das entrevistas confeccionadas neste artigo foram empregadas algumas etapas metodológicas que são exemplificadas neste texto como: pré-entrevista (primeiros contatos, esclarecimento de como se chegou aos colaboradores, de quais os objetivos do projeto e alguns procedimentos, conhecimento prévio da história pessoal e preparação do material e da pauta), entrevista (gravação, agradecimentos e meios de contato), caderno de campo, transcrição, textualização, transcriação, pós-entrevista (conferência, autorização para uso da entrevista e carta de cessão), elaboração de resumo para arquivamento, arquivamento, publicação e devolução aos entrevistados.

Os discursos explicativos dos imigrantes bolivianos apontam, em tempos diferentes, os porquês da escolha de determinadas cidades do Brasil em detrimento de outras. Sabemos que existem diferenciados fatores que impulsionam a emigração, assim como existem variados condicionantes que interagem na escolha da cidade, ou, de países, em sua grande medida, condicionantes econômicos. Na sequência, visualizaremos os relatos dos sujeitos e suas explicações pessoais para o deslocamento.

\section{Ensejos para a emigração}

Elencar os objetos de escolha do país e da decisão de emigrar não é tarefa fácil; imbuídos pela mídia, que quase sempre repete a frase que se tornou um chavão da imigração boliviana: "migram porque buscam melhores condições econômicas e qualidades de vida"; e muitas vezes repetidas e interiorizadas como a explicação macro para os motivos da emigração, quase sempre utilizadas pelos narradores da pesquisa. Foi somente com a inserção em campo e nos desdobramentos das entrevistas que pudemos nos aproximar das explicações pessoais, e em alguns momentos, até de cunho coletivo para entender como os emigrantes bolivianos construíram suas justificativas para a emigração. Partindo dessa premissa, não queremos negar os aspectos econômicos embutidos nas vidas das pessoas, mas apontar que, vinculados aos condicionantes macroestruturais, as pessoas criam justificativas pessoais, que expressam a subjetividade, como mecanismos que podem ser interpretados como condicionante sócio-histórico.

Existem variados posicionamentos sobre os motes que condicionam os sujeitos a emigrarem. Duas correntes explicativas, a marxista e freudiana, mobilizam argumentos específicos sobre os condicionantes sociais. As vertentes marxistas percebem a afirmação de

que os homens (sic) fazem a história, mas apenas sob condições que lhe são dadas'. Seus novos intérpretes leram isso no sentido de que os indivíduos não poderiam de nenhuma forma ser os 'autores' ou os agentes da história, uma vez que eles podiam agir apenas com base em condições históricas criadas por outros e sob as quais eles nasceram, utilizando os recursos materiais e de cultura que lhes foram fornecidos por gerações anteriores (Hall, 2003, p.35).

Por sua vez, a vertente freudiana promove uma ruptura do sujeito racional iluminista, pois

A teoria de Freud de que nossas identidades, nossa sexualidade e a estrutura de nossos desejos são formadas com base em processos psíquicos e simbólicos do inconsciente, que funciona de acordo com uma 'lógica' muito diferente daquela da Razão, arrasa o conceito do sujeito cognoscente e racional provida de uma identidade fixa e unificada (Hall, 2003, p.36).

Percebemos com as vertentes acima, que existem variadas possibilidades interpretativas para entender

1 Os trechos das entrevistas utilizadas neste artigo encontram-se na íntegra na pesquisa de mestrado Trânsito de Identidades e Estratégias de Negociação Familiar: deslocamentos populacionais entre a Bolívia e o Brasil. Dissertação (Mestrado em História Social) - Faculdade de Filosofia, Letras e Ciências Humanas, Universidade de Universidade de São Paulo, São Paulo, 2011. E-mail: vanessa. narracao@gmail.com 
o deslocamento das pessoas no tempo e no espaço contemporâneo. Aqui, elencamos os argumentos dos colaboradores da pesquisa para entender a complexidade dessa emigração.

Ao se tratar do contexto histórico boliviano, em grande parte, é difícil perceber em meios às dificuldades locais outras explicações que legitimam a manutenção da emigração, mesmo para os entrevistados que partiram do seu país sem o planejamento para o ato da emigrar.

A colaboradora Aidé disse que os motivos de escolha estiveram diretamente relacionados aos problemas da relação conjugal que sua irmã, Carmen, vivenciava no momento. Carmen estava passando por um processo de separação, tendo de arcar com os cuidados da criação de três filhos. Preocupada com a situação da irmã, Aidé resolve vir para o Brasil para trabalhar na oficina de costura coordenada por seu ex-cunhado. Ao chegar, percebeu que não foi bem-aceita no círculo do trabalho e, como a relação conjugal da irmã passava por problemas, as duas resolvem evitar as humilhações empregadas pelo seu cunhado e irem trabalhar na oficina do primo do cunhado, local onde também depara com a violência psíquica deflagrada pelo patrão. Vejamos abaixo as explicações que Aidé elaborou sobre esse momento de sua vida.

Eu cheguei em São Paulo, no Brasil, em dezembro de 2005. Cheguei com gana, com vontade de trabalhar. Também porque vim com a intenção de ajudar a minha irmã que na época estava em processo de separação, porque tinha muitos problemas com o seu esposo. Quero muito ajudá-la, ajudar os seus filhos e também ajudar os meus pais, pois ficaram na Bolívia. (Aidé, mais de 30 anos, residente de São Paulo/SP, entrevista realizada em 16/7/2006)

Conflitos e problemas no cenário migratório foram frequentes nos relatos dos bolivianos entrevistados. Estudiosos, tais como Valéria Magalhães[2], Samira Adel Osman [ $\left.{ }^{3}\right]$ descrevem em suas pesquisas momentos onde os papeis sociais e os níveis de cobrança individual e familiar reconfigurados nos países de destino são comuns, desenvolvendo 'brigas' entre os indivíduos.

As explicações construídas por Luis Vasquez é de que seu deslocamento estava associado aos planos de continuidade aos estudos. O colaborador, com sua esposa Lordes, não tinham a intenção de vir para o Brasil, mas sim seguir para a Espanha ou Estados Unidos; mas como a sua esposa havia finalizado a curso de medicina e ouviu de um amigo que a melhor opção de trabalho seria investir na continuidade de estudo no Brasil, resolveram arriscar as 'fichas' no Brasil.

Lembro que eu e a Lordes ficamos no terminal de Campo Grande sem saber o que fazer... "O que fazer da vida? Voltar para Bolívia? Vai ser um fracasso.” A família ficou na expectativa porque viemos para o Brasil para estudar. A família fica muito entusiasmada. "O seu filho tá indo para outro país." (Luis Vasquez, mais de 40 anos, residente de São Paulo/ SP, entrevista realizada em 05/10/2006)

Marta, seus dois irmãos e seu pai - diferindo das explicações acima - resolveram sair da Bolívia durante a década de 1960 em decorrência do falecimento da matriarca da família. Victor Patzi, o patriarca, decepcionado com os rumos que a vida havia desenhado, pois não queria continuar com a prática de 'beber sem limites' como muitos irmãos e primos tinham o costume de fazer, resolveu emigrar para o Brasil para não continuar com os hábitos do local. Vejamos abaixo os argumentos de Marta.

A minha mãe trabalhava e ganhava de um lado e papai ganhava de outro, ela acabou ficando doente. E o que aconteceu? Ela começou a sofrer do coração, isso foi o que diziam na época, que era hereditário porque a minha avó faleceu com o mesmo problema que a minha mãe, do coração, e o ácido foi indo pros pulmões; onde ela ficou com problema de pulmão também, era a tuberculose, que hoje tem cura, mas naquele tempo não havia, as pessoas morriam. Tanto que ela faleceu com trinta e um anos, eu fiquei com oito anos de idade, o meu irmão ficou com quatro ou cinco anos, e a minha irmãzinha caçula ficou, deve ter ficado com três a dois anos, ela ainda mamava... (Marta Patzi, mais de 60 anos, residente de São Paulo/SP, entrevista realizada em 24/4/2009)

O parceiro de Marta resolveu sair da Bolívia com o projeto de estudar e ter uma profissão. Preten-

2 O Brasil no Sul da Flórida: Identidade, Subjetividade e Memória. Tese (Doutorado em História Social) - Faculdade de Filosofia, Letras e Ciências Humanas, Universidade de Universidade de São Paulo, São Paulo, 2006.

3 Entre o Líbano e o Brasil: Dinâmica Migratória e História Oral de Vida. Tese (Doutorado em História Social) - Faculdade de Filosofia, Letras e Ciências Humanas, Universidade de São Paulo, São Paulo, 2007. 
diam desenvolver esses objetivos no Brasil, até porque Marcos veio em um período em que o Brasil detinha um acordo bilateral com algumas universidades bolivianas na década de 1970 e, ao mesmo tempo, pretendia realizar um curso técnico e retornar para a Bolívia. O projeto do retorno não foi efetivado, pois acabaram casando-se e constituindo família em São Paulo. Os vínculos familiares foram maiores, e Marcos desenvolveu o ofício de técnico de máquina de escrever no Brasil.

Havia um projeto de partida, tinha muita vontade de sair, mas a minha necessidade era aprender, queria ter um ofício, queria sair da Bolívia para aprender uma profissão. (Marco, mais de 60 anos, residente de São Paulo/SP, entrevista realizada em 14/5/2009)

Marcos continuou com suas explicações ao descrever alguns acontecimentos históricos que podem servir, também, como uma explicação possível para sua escolha.

Sei que essa revolução que ocorreu na Bolívia em 1952 mudou um pouco a configuração das cidades andinas e do altiplano boliviano. Antes desse movimento uma minoria de pessoas eram donas das terras, tinham grandes fazendas. $\mathrm{O}$ pessoal da fazenda tinha trabalho, tinham serviços. Mas o pessoal fez a reforma agrária. Como não tinha mais fazenda o pessoal começou a migrar para a cidade, para La Paz, mas não achou emprego. Claro, no primeiro momento foram as famílias que saíram, onde muitos enviavam seus filhos a ir para a escola e, quando cresciam conquistavam trabalho. Atualmente, faz uns dez ou vinte anos que essas pessoas do interior da Bolívia estão vindo para o Brasil. Antes, partiam só os filhos da revolução, daqueles que antes não tinham terras para morar. (Marco, mais de 60 anos, residente de São Paulo/SP, entrevista realizada em 14/5/2009)

A revolução que Marcos cita é a revolução de 1952, que acarretou uma melhoria ao incluir os camponeses indígenas nas terras que foram repartidas. Para a historiadora Mota (2009), esses processos refletiam as condições de vida dos camponeses originários e, embora tenha alcançado níveis de distribuição de terras, nem todos puderam usufruir das reformas empregadas pelo governo.

Como não encontram empregos nas cidades, o que eles iriam fazer na Bolívia? Simplesmente uns foram para as cidades próximas da fronteira, outros migraram porque achavam que iriam melhorar de vida e que iriam ganhar rios de dinheiro. E outros, como eu, seguiam alegres pensando em estudar e trabalhar. Acho que ocorreu o mesmo para a Argentina.

Sei que Argentina e o Brasil são polos de atração. Muitos vão para Chile, para o Peru porque faz fronteira com a Bolívia, outros partiam para a Argentina porque tinha indústria ou para trabalhar na agricultura ou hortifruiti. Os bolivianos vêm para o Brasil por causa das indústrias, só que assim que chegam aqui se deparam com a falta de documentos e aí o único lugar que podem trabalhar é na costura. A costura é uma coisa mais simples para trabalhar, pois não é necessário ter documentos. A pessoa que tem firma precisa dos bolivianos que são mão de obra barata, ainda sem documentos, você pode pagar ou não pagar porque não tem quem regule isso. O pessoal que volta para Bolívia com pouco dinheiro tem outra visão. (Marco, mais de 60 anos, residente de São Paulo/SP, entrevista realizada em 14/5/2009)

Ainda durante a década de 1970, Marcos atrelou ao fator de escolha de migrar para o Brasil o fato de as cidades como São Paulo e Buenos Aires estarem num patamar industrial diferenciado das cidades bolivianas. Quando não direcionados para indústrias, dirigiam-se para o comércio de frutas e verduras $\left.{ }^{[}\right]$. Marcos ainda atrela a necessidade de ter um trabalho digno como a premissa para migração de seus patrícios às capitais industrializadas.

Atualmente é assim, uma parte das pessoas que saem vão para o exterior, grande parte vai para os Estados Unidos, para Europa e tem outra visão. Essa ideia é semelhante na Bolívia. Quem vem de cidade pequena, do interior, chega em La Paz e tem outra visão, mas se chega em São Paulo a visão amplia. Muitos saem de suas cidades para ampliarem suas concepções de mundo, outros por necessidade de trabalhar, e outros por diversos motivos, pois não existe apenas um padrão de escolha. (Marco, mais de 60 anos, residente de São Paulo/SP, entrevista realizada em 14/5/2009)

4 Principalmente as pessoas que escolhiam a Argentina como destino, grande parcela das pessoas não tinham documentos e acabavam sendo inseridas na colheita de frutas e verduras das províncias argentinas. Para maiores detalhes consultar o artigo de CAGGIANO, Sergio. ¿Bolivianos? En dos ciudades ¿argentinas?. Identidades sociales en procesos migratorios contemporáneos. Informe final del concurso: Culturas e identidades en América Latina y el Caribe. Programa Regional de Becas CLACSO. 2001. Disponivél: http://bibliotecavirtual. clacso.org.ar/libros/becas/2000/caggiano.pdf. acesso em 20/06/2009. 
São diferenciados os motes explicativos da migração, querer enquadrar todas as explicações por meio de um único modelo analítico seria empobrecedor. E é com a perspectiva de ampliar os fatores explicativos que envolvem o processo migratório boliviano que essa pesquisa se justifica. Relativizar as explicações é uma das perspectivas deste artigo. Sendo assim, é importante entender tanto o cenário social da qual saíram muitos emigrantes dessa pesquisa quanto as suas explicações pessoais, que comumente estão amparadas nas experiências de vida, como também, no entrelaçamento com outras experiências na metrópole paulistana.

As pessoas com menores poderes aquisitivos escolhem os países circunvizinhos da Bolívia; mas aqueles que detêm recursos para custear passagens e maiores deslocamentos vão para Europa, principalmente, Espanha e Itália para trabalhar nos setores de serviços femininos: cuidados de crianças e de idosos. Alguns sociólogos bolivianos que estudaram as migrações para a Europa declaram que as mulheres formaram o grande contingente de mão de obra, redesenhando, assim, os papéis sociais exercidos na migração, pois se num período de menos de 40 anos, quando os homens eram os responsáveis a enviar as remessas para suas casas e famílias; agora, em virtude dos campos de trabalho, as mulheres bolivianas estavam deixando os filhos aos encargos dos maridos, tias, avós; e seguiam para o exterior para trabalhar e enviar as remessas para suas famílias.

O irmão de Marcos, Leo, atrela as explicações de partida ao fator trabalho, pois muitos chegaram a terminar os estudos e cursarem graduação, mas não há campos de aplicação da força produtiva e acabam optando pela emigração como forma de minimizar a frustração, justificando, assim, a falta de oportunidade em dar continuidade aos projetos não desenvolvidos em sua pátria.

Acredito que muitas pessoas tenham vindo para o Brasil em busca de trabalho, porque na Bolívia não tem emprego, apesar de ter um custo de vida barato. Você consegue comprar comida, roupas, calçados; mas trabalho não se arruma, e me pergunto por quê? Acho que nós não temos indústria, não temos montadora, não temos fábrica; as que temos são pequenas e não comporta o número de desempregados que existe por lá. Então, a juventude, pessoas com dezoito, dezenove, vinte anos, termina o ensino médio, entra na faculdade, e ao saírem não sabem em que aplicar os seus conhecimentos porque não há campo de trabalho. Então, alguém chama e diz: "No Brasil você vai ganhar, na Argentina está melhor ou no Chile." São três países escolhidos pelas pessoas para trabalharem. Antigamente, a Europa era a escolhida, agora ficou difícil ir para Europa. (Leo, mais de 40 anos, residente de São Paulo/SP, entrevista realizada em 13/4/2010)

Na sequência, Leo explicou que mesmo aqueles que terminam os cursos universitários emigraram com a intenção de realizar seus estágios no Brasil, para em seguida tentar permanecer por meio de vínculos empregatícios, mas a concretude dos fatos não permitiu tal situação, pois se para os nacionais ter um emprego digno na contemporaneidade tornou-se uma meta e não uma realidade, para os estrangeiros tal realização ficou apenas no plano do desejo, pois muitos problemas se impõem, principalmente os relacionados ao estatuto jurídico de falta de documentos para permanecerem "legais" no Brasil.

Por que vem da Bolívia? A maioria vem de La Paz, Potosí e Oruro. Podemos fazer a mesma comparação com o pessoal do norte, do nordeste, do Ceará, da Bahia que vem trabalhar em São Paulo ou no sul do Brasil. Agora, a maioria dos bolivianos ia para Europa, principalmente, pessoas que terminaram cursos universitários e que tem condições de arcarem com os gastos do deslocamento. Muitos engenheiros foram para os Estados Unidos trabalhar de pedreiro na construção civil; tem formação, mas no exterior tem que trabalhar, mesmo não sendo no seu setor. Então, é sempre a mesma coisa; e o boliviano vem para cá para trabalhar. A não ser que ele vá estudar; não são todos, um ou outro terminaram a faculdade e ficam trabalhando, outros vem realizar estágio e ficam. (Leo, mais de 40 anos, residente de São Paulo/SP, entrevista realizada em 13/4/2010)

As regiões do altiplano boliviano, como os estados citados por Leo, são tidos como departamentos onde um grande número de pessoas sai para outros estados bolivianos, principalmente para cidades como Santa Cruz de la Sierra. O movimento de pessoas para as metrópoles bolivianas é de fluxo contínuo. Informação que revela que são desses departamentos que partem as pessoas que vêm para o Brasil.

Diferentemente das informações acima, o senhor Guillermo, revelou que a primeira vez que ouviu um amigo falar do Brasil estava relacionado à cidade do Rio de Janeiro, tão caricata por representar um dos berços do samba e da bossa nova. As lembranças de Guillermo relacionadas ao Rio de Janeiro são repercussões de uma mídia internacional que pregava a crença no Brasil como "país do futuro", como apanágio do 
Artigos

Carnaval, ou como "país tropical”. Por vivermos numa nação onde as contradições sociais se transformam em samba, chega ao cenário boliviano como uma atitude da cidade desejada para se viver, pois aglutina em seu espaço religião, música e futebol; esferas sociais fortes na cultura hispano-americana.

Também gosto de ouvir as músicas bolivianas, ultimamente, não tanto porque já ouvi muito, me cansei. Gosto de conhecer coisas novas, saber de outras coisas, desde que sejam boas. Acredito que tenha vindo para o Brasil porque os meus amigos comentavam muito do Rio de Janeiro, que o Rio era maravilhoso, sonhava em viver no Rio. Na época, era fabricante de para-água, fabricava guarda-chuvas no Bom Retiro, onde vendia para Rio, Belo Horizonte, Juiz de Fora, e mais algumas cidades. (Guillermo Salazar, mais de 70 anos, residente em São Paulo/SP, entrevista realizada em $7 / 7 / 2009)$

O narrador Guillermo Salazar revela o motivo, em sua esfera subjetiva, que o trouxe até o Brasil. Isso demonstra que o campo da subjetividade é um motor fértil das escolhas pessoais, de tal modo, não podemos negar a flexibilidade do devir que pode motivar a escolha de tais países em detrimento de outros.

Penso que saí da Bolívia por que não tinha mais família, meus pais tinham falecido; e depois juntou a minha curiosidade em conhecer outro país, o gosto pela música e filmes brasileiros. Essas coisas me chamavam atenção, mas nunca havia planejado permanecer durante tanto tempo, para mim é um sonho ter ficado até hoje. Quando penso o que passei, parece mentira ter conseguido ficar tanto tempo em São Paulo e só tenho noção de quanto tempo passou quando volto para Bolívia. Desde pequeno vivo sozinho, mas como sou muito religioso, acabei preenchendo com a fé os vazios da minha vida. (Guillermo Salazar, mais de 70 anos, residente em São Paulo/SP, entrevista realizada em $07 / 7 / 2009)$

O senhor Guillermo é órfão desde criança; os percalços que teve que enfrentar e continuar em 'pé' podem ser explicados pela sua matriz religiosa, já que é um católico convicto, mas que não deixa de agradecer o sucesso de ter se tornado um comerciante conhecido no Brasil. Ele arremata com o seu sincretismo à moda brasileira:
“ascendemos as velas e oferecemos a Mãe Yemanjá, agradecemos pela minha vitória, meus fracassos, minhas penas, minhas alegrias e pedi por todos os meus amigos. Eu acho que é um agradecimento muito lindo, sou muito religioso, muito espiritualista. Sempre agradeço a Deus por tudo". (Guillermo Salazar, mais de 70 anos, residente em São Paulo/ SP, entrevista realizada em 7/7/2009)

Percebemos que as matrizes culturais, religiosas e familiares são campos que configuram as visões de mundo dos sujeitos em diferentes culturas e que interferem nos padrões de escolha das pessoas.

Em seguida, a narradora Ema traçou o porquê de seu deslocamento para o Brasil, fazendo jus a um setor de trabalho que foi desempenhado por muitas bolivianas que vieram na década de 1960: o trabalho doméstico.

Eu estou no Brasil há 54 anos. Na época que cheguei não havia boliviano. Os Bolivianos começaram a chegar depois de 20 anos que estava aqui. Até então, era raro ver um. Quando vim da Bolívia, vim com contrato de trabalho, como pacho; vim com uma família de judeus, a mulher era judaico-alemã e o marido dela era sírio. Tinha um contrato de trabalho que perdurariam dois anos. (Ema, mais de 70 anos, residente de São Paulo, em São Paulo, entrevista realizada em $5 / 11 / 2009)$

O setor de serviços tidos como femininos: cuidar de idosos, babás e empregadas domésticas [5] tem crescido nos últimos tempos com relação à mão de obra boliviana no sudeste do Brasil, uma vez que muitas mulheres conseguiram dar entrada no pedido de regularização da documentação com a anistia que ocorreu em 1990, e outras saíram do setor da costura e foram trabalhar em outros campos de serviços. Tal escolha é visível devido ao fato de muitas mulheres não terem vínculos familiares no Brasil, o que facilita com relação ao quesito de ter que dormir no emprego; exigência de algumas famílias de classe média brasileira. Um dado importante a ser considerado é com relação à faixa salarial desses empregos, pois geralmente estão cotados

5 Matéria vista no Jornal Folha da São Paulo e publicado no blog http://sergyovitro.blogspot.com/2011/02/latina-busca-vaga-de-domestica-no-pais.html acesso em 20/2/2011. 
acima de $\mathrm{R} \$ 800$; o que tem agradado às pessoas que seguem para esses serviços, pois ao ser convertido em moeda boliviana, quadruplicam o valor somado; além de somar o fato de não pagar aluguel e alimentação no trabalho. No entanto, a narradora Lídia argumenta outros fatores que a trouxeram para o Brasil.

Nasci na Bolívia na capital Trinidad, departamento de Beni. Foi lá que cresci e me criei até o início da fase adulta. Quando fui fazer vinte e dois anos apareceu um grupo de amigos que vinham para o Brasil e acabei embarcando junto, pois tinha paixão de conhecer o Brasil, de entrar em contato com a música e cultura brasileira, daí resolvi ir também. (Lídia, mais de 70 anos, residente de São Paulo, em São Paulo, entrevista realizada em 24/5/2010)

Diferentemente das explicações acima, a narradora Lídia, residente no bairro de Higienópolis em São Paulo e pertencente à rede social dos amigos de Marta e Ema, descreveram os motivos de emigrar como atrelados à curiosidade de conhecer de perto a cultura brasileira e estudar português. É importante apontar que durante a década de 1960 os expoentes da cultura brasileira no cenário internacional estavam atrelados ao cinema novo, ao futebol de Pelé, às músicas do gênero bossa nova e aos sambas, internacionalmente reverenciados por Carmen Miranda. As lembranças culturais de Lídia e do narrador Guillermo estão diretamente vinculadas às expressões de seu tempo.

O cine Olido era luxuoso; o metrô e o cinema pareciam um palácio. Avenida São João, onde desfilavam os blocos de Carnaval e as Escolas de samba, era magnífico. O carnaval começava na avenida São Bento e descia a avenida São João. Nesse tempo não tinha viaduto, era só a Avenida São João. Na praça da Avenida São João havia uma arquibancada que descia para a avenida, inclusive, o prefeito da época era o Faria Lima. Olha a minha cabeça, o Faria Lima mandou fazer isso. Depois da Ipiranga, ele mandou fazer outra arquibancada para incluir o número de pessoas. $\mathrm{O}$ atual cine Olido era na Avenida São João, na Avenida Ipiranga tinha outro cinema enorme; sei que eram quatro cinemas que tinham na Avenida São João e um teatro com o nome da atriz que morreu aos 102 anos, Teatro Derci Gonçalves, atualmente fechado. Aos poucos os lugares bonitos da cidade foram se perdendo. (Lídia, mais de 70 anos, residente de São Paulo, em São Paulo, entrevista realizada em 24/05/2010)

Assim como a paisagem transforma-se com a ação humana, as lembranças e os espaços modificam as concepções que temos do mundo.

Meu nome é Carlota Munhoz Torrico e vim para o Brasil porque os meus pais não queriam que eu namorasse, pois o rapaz que gostava era humilde e trabalhava com conserto de bicicletas. Atualmente, os pais querem que seus filhos se casem com médicos, advogados, pessoas que possam oferecer estabilidade. Naquele tempo, antes de sair da Bolívia a minha irmã disse: "Você irá para o Brasil estudar, trabalhar." Ainda na minha terra formei-me em contabilidade geral e trabalhei durante um período num escritório. Lembro que minha irmã falou: "Acho que se você for para o Brasil irá ganhar muito mais.” (Carlota, mais de 50 anos, residente de São Paulo/SP, entrevista realizada em 19/5/2010)

As histórias de amor raramente aparecem como fatores da escolha de emigrar. Às vezes, as pessoas camuflam essas informações por meio dos condicionantes macroeconômicos, mas Carlota inicia a narrativa revelando o que poderia ser apenas um detalhe, porém, essa minúcia reconfigurou sua vida. O Brasil não foi sua primeira passagem por terras estrangeiras. Ainda na juventude, Carlota foi para os Estados Unidos morar com uma de suas tias; ficou um período e voltou porque seu visto de estudante havia vencido. Carlota planejou ao retornar para a Bolívia, realizar um curso de inglês e tentar a sorte nos Estados Unidos, mas seu pai não deixou isso acontecer. Carlota fez um curso superior e já estava trabalhando quando surgiu a vontade de ir para o Brasil. A colaboradora tem uma irmã que morou em São Paulo, que por sua vez foi dona de uma oficina de costura. Assim, a narradora descreve que veio com o intuito de trabalhar como contadora e prosseguir em seus estudos, porém acabou no nicho da costura.

Sou Maria Luiza Mamani Vasquez, morava em La Paz, Bolívia. Era comerciante, mas como perdi muito capital acabei perdendo tudo que tinha conquistado; assim, resolvi vir para o Brasil junto com o marido e os filhos. (Maria, mais de 50 anos, residente de São Paulo, em São Paulo, entrevista realizada em 7/7/2010)

A narradora Maria, muito próxima dos argumentos de seu esposo Ilfredo, descreve que veio devido aos prejuízos nos negócios da família. Em La Paz era comerciante e trabalhava com seu marido nas vendas 
de mercadorias estrangeiras que seu esposo comprava no Brasil, na Argentina e no Paraguai. Assim, Ilfredo descreve abaixo:

Meu nome é Ilfredo Flores Aguilar e durante um bom tempo da minha vida trabalhei com transporte de mercadorias no circuito Bolívia, Paraguai, Argentina, Peru e Brasil. Só parei de trabalhar nesse ramo devido ao fato de ter perdido muito dinheiro com a Receita Federal porque as mercadorias não tinham nota fiscal. Na Bolívia nós dizemos "Aduana de polices", mercadorias sem documentação. Perdi o meu caminhão cheio de mercadorias, um valor de quase 80 mil dólares. E esse foi o fator primordial pelo qual resolvi vir para o Brasil. (Ilfredo Flores, mais de 50 anos, residente de São Paulo, em São Paulo, entrevista realizada em 4/2/2010)

As motivações de Maria e Ilfredo são da esfera econômica. Buscavam compor uma renda no Brasil, retornar e pagar as dívidas que deixaram em seu país, porém acabaram ficando e hoje produzem e vendem pães bolivianos na praça Kantuta e adjacências.

A narrativa de Jenny Caballero foi norteada pelas divergências e pelos questionamentos dos papéis sociais de gênero presenciados em sua vida. Jenny não titubeia e é enfática desde o início ao dizer:

Meu nome é Jenny, tenho 26 anos e nasci em La Paz. A minha vida na Bolívia era muito mais tranquila, estudava, trabalhava, gostava de passear. E foram por variadas razões, algumas que ainda não sei explicar, que vim parar no Brasil. Uma das razões é que casei com um rapaz que é filho de boliviano e sua família é dona de uma oficina de costura na cidade de São Paulo. (Jenny Cabalero, mais de 25 anos, residente de São Paulo/, entrevista realizada em 14/4/2010)

As motivações do plano afetivo são tidas como complementares quando encaradas com o olhar marxista de análise, mas aqui tem um peso equivalente aos problemas sociopolíticos, pois Jenny não foi para o Brasil somente porque casou, mas porque quer construir projetos de futuro fora do contexto "machista" da qual advinha. Jenny quer ditar as regras de sua vida sem a autoridade da palavra legítima do provedor de sua velha morada: seu pai. Quando a mãe de Jenny faleceu, a narradora encontra um campo fértil para a libertação do seu 'eu' aprisionado, pois almeja dar continuidade nos estudos em outro país, trabalhar e viver neste país. Tão diferente da vida de advogada na qual vivia, a entrevistada teve que rearticular sua vida dentro de um casamento onde teria que viver, a princípio, com a família de seu marido, com um agravante que vai reposicionar sua percepção de mundo: trabalhar e residir no Brasil na oficina de seus sogros. Sabendo apropriar-se dos meios nos quais vivia, Jenny estuda e aprende português em dois anos, trabalhou como voluntária durante um período na Pastoral do imigrante de São Paulo; e com o processo de anistia, saiu do nicho das oficinas e trabalha como tradutora de espanhol/português em uma ótica na Rua Celso Garcia, no Brás; sendo mediadora de vendas para a clientela hispânica e africana do bairro.

A seguir, a narradora Claudia, entrevistada em La Paz, argumentou os motivos que a levaram a partir para São Paulo, como também, o que motivou o seu retorno para La Paz.

Quando o meu irmão resolveu ir para o Brasil, foi algo improvisado, o meu irmão estava lá há dois anos, voltou e disse que queria que eu fosse com ele. Eu não queria ir, os meus planos não eram sair da Bolívia. Ele foi e depois de uns meses voltou, depois de um ano lá, se não estou enganada; e no penúltimo ano que ele veio, acho que foi em 1998, queria que eu fosse. Mas estava namorando e não queria deixar o namorado só. O namorado já tinha ido para o Brasil uns anos atrás. Depois de alguns meses que estávamos juntos, ele resolveu ir para tentar abrir um negócio no Brasil, um escritório próprio, não, as pessoas que trabalhavam com ele decidiram abrir uma oficina, e ele perguntou se eu poderia ir para ajudá-lo. Sei que resolvi ir, mas tinha que deixar o meu filho na Bolívia, não podia levá-lo porque ele era bebê; tinha 3 anos e meio, fiquei pensando: "Deixo com quem?", e aí deixei com a senhora que trabalha aqui na pousada onde atualmente trabalho, com a Sandra. (Claudia, mais de 25 anos, residente em La Paz/Bolívia, entrevista realizada em 1/9/2010)

Apesar de Claudia ter um irmão residindo em São Paulo, a colaboradora resolveu partir em virtude do convite de seu namorado, pois ambos tinham parentes e amigos que trabalhavam no setor da costura, mas todos os convites feitos até o presente momento foram recusados em consequência da existência de seu filho. Claudia teve uma infância difícil, aprendeu cedo o valor do trabalho, uma vez que seus pais faleceram quando era adolescente. No momento em que a entrevista foi gravada, ela trabalhava na pousada El Carretero na parte central da cidade de La Paz. Quando resolveu seguir para São Paulo, não imaginou que fosse 
compartilhar a casa com outros grupos de pessoas, o que fez que a relação entre ela e seu namorado ficasse conflituosa. E depois de um período de desentendimentos entre os sócios e a esposa do seu namorado, resolveu retornar para sua terra e cuidar de seu filho.

Um fator importante para refletirmos é que Claudia não foi a primeira mulher boliviana que partiu para trabalhar em outro país e deixa seu filho e irmãos menores aos cuidados de parentes ou amigos próximos; pois, segundo pesquisas recentes que foram realizadas por sociólogos, antropólogos e psicólogos, esse processo reflete a feminização da migração boliviana, porque se outrora eram os chefes de família que deixavam a Bolívia à procura de trabalho para encaminhar as remessas para seus entes queridos, nos últimos 20 anos, cada vez mais, mulheres deixam seus lares em busca de melhores alternativas para a manutenção da família que ficou na Bolívia. Esse elemento foi relevante, pois afeta as relações parentais e afetivas das pessoas que partiram e dos que ficaram, porque a partir desse episódio, haverá uma redefinição dos papéis de gênero, onde homens ficam para a criação dos filhos e a mulheres saem para ocupar nichos de trabalho tidos como 'femininos'.

A senhora que ficou cuidando do meu filho quando parti para o Brasil é madrinha dele e gosta de cuidar dele desde pequenininho. Nesse período que estava com o meu filho, comecei a trabalhar aqui na pousada e o meu irmão mais novo deixou de estudar, antes ele até trabalhava durante as férias; mas depois dos 15 anos ele se apaixonou, começou a andar em más companhias, deixou de estudar; estava na idade da loucura, queria namorar, mas só tinha 15 anos. Quando nos inteiramos que ele estava andando em má companhia, começamos a ficar preocupados; e ele estudava à noite, e às vezes faltava à aula, às vezes não dormia em casa e nessa ocasião, falei com o Roberto e decidimos que o David, irmão mais novo, iria para o Brasil trabalhar.

Fomos conversar com o meu irmão caçula: "David, queres ir para o Brasil? Tu vais, trabalha dois anos, volta para cá e vai estuda de noite." Porque aqui existe a possibilidade de fazer em dois anos o ensino médio. Eu dizia para o meu irmão estudar porque eu comecei a trabalhar e não terminei os estudos. Ele terminou o ano e foi com o Marco Antônio trabalhar no Brasil. (Claudia, mais de 25 anos, residente em La Paz/Bolívia, entrevista realizada em 1/9/2010)

Além de Claudia, o irmão mais novo também foi para o Brasil trabalhar com seu irmão mais velho, que se encontrava em São Paulo. Claudia e outro irmão que ficaram na Bolívia resolveram conversar com irmão caçula em virtude de ele andar em más companhias, resolvendo assim, que a melhor opção para o mesmo seria desvincular-se dos 'vícios' que estava exposto e passasse uma temporada trabalhando no Brasil para depois retornar e prosseguir os estudos.

Essa perspectiva micro, que surge com a história do tempo presente, impõe a necessidade de construirmos novas formas de compreendermos os movimentos migratórios humanos, pois, para o sociólogo e estudioso da migração Abdelmalek Sayad (1998), o fenômeno da migração contemporâneo é complexo e precisa ser entendido a partir de diversos setores do conhecimento. Em sua concepção, a migração é o movimento de pessoas no espaço físico e social, em caráter definitivo ou por tempo longo. É um jogo de paradoxos entre i/emigração como um processo constituinte de duas faces de um mesmo fenômeno: o processo migratório em seus diversos ângulos: à saída do país de origem e imigração e a chegada e permanência no país que o abriga. Em suma, Sayad compreende o fenômeno da migração como "fato social total", pois é um processo que carece ser interpretado a partir de várias perspectivas do conhecimento. Neste complexo jogo, poderemos entender o fenômeno da migração como ascendência, como experiências de deslocamentos, mudanças de espaços e valores, sendo que "o espaço dos deslocamentos não é apenas um espaço físico, ele é também um espaço qualificado em muitos sentidos, socialmente, economicamente, politicamente, culturalmente."\%

\section{Considerações sobre a diáspora}

A Bolívia, assim como o México, Porto Rico e Equador, é um país diaspórico; e a emigração é um fenômeno histórico-estrutural em que uma parcela significativa de pessoas escolhe outros países como formas estratégicas para sua sobrevivência. O crescimento acelerado de diversos grupos de pessoas dentro da Bolívia nos obriga a pensar no caso boliviano como sendo significativo para os estudos migratórios internacionais da América Latina.

6 Ver SAYAD, Abdelmalek. A Imigração ou os Paradoxos da Alteridade. SP, EDUSP, 1998, p.15. 
O sociólogo boliviano Alfonso Hinojosa Gordonava descreveu em um dos seus livros que um dos elementos importantes ao analisarmos a migração dos bolivianos deve ser a constituição da Bolívia enquanto nação, pois

Trata-se de reconhecer que em nosso país, sumamente heterogêneo, se sobrepõem diferentes tempos, culturas, economias e nacionalidades; e, portanto, dinâmicas e lógicas demográficas distintas. A Bolívia não terminou de resolver o problema nacional e não pode constituir-se num Estado que reflete a nação. É dizer que o projeto de um Estado-nação que, em termos clássicos, representa uma nacionalidade, culturas (homogênea) e um território, foi um projeto inacabado, inconcluso. O projeto nacional tratou por implementar-se de diferentes maneiras durante nossa vida republicana. Em um primeiro momento, por meio da total negação e exclusão das diferenças e da existência de culturas e diferentes nações; assim se constituiu uma dupla República, com uma bolivianidade que se reproduziu em alguns centros urbanos, rodeada por outra bolivianidade em que prevalecia uma variedade de culturas que eram ignoradas e as quais só era lembrada no momento da cobrança de impostos, quando queriam mão de obra barata ou de soldados dóceis para as aventuras militares da outra Bolívia. Posteriormente, com a Revolução de 1952, tratou-se de constituir um Estado-nação por meio de transformações, desenvolvidas e administradas pelo Estado, que buscava a integração do conjunto da população boliviana. Com este objetivo decretou-se o voto universal, nacionalizou-se as empresas produtivas mais importantes, apostou-se na constituição de um mercado nacional, e a reforma agrária foi implementada (para expandir o mercado e integrar os indígenas, desde então proprietários de suas terras) inicia-se a denominada marcha para o Oriente e já se incentivava o desenvolvimento de um polo econômico em Santa Cruz como uma maneira de integrar geograficamente o país. Finalmente, aboliu-se a palavra índio para nomeá-los como povos originários, rebatizando-os como campesinos (delimitando sua identidade no âmbito produtivo). Em todo caso, os movimentos populacionais vividos intensamente dentro das fronteiras nacionais devem ser também considerados a partir de uma perspectiva maior que os vínculos entre Estados nacionais, e as análises da dinâmica interna e externa. (HINOJOSA GORDONAVA, Alfonso R. 2009, p.18, tradução minha).

Os argumentos levantados por Alfonso Hinojosa Gordonava são de que não podemos entender o processo migratório boliviano como um fator recente, pois os deslocamentos dos povos originários dentro do território bolivianos advêm de um longo processo histórico pré-hispânico, de tal modo, para o autor, as migrações contemporâneas possuem elementos que a vinculam com processos históricos anteriores, principalmente, os vínculos de parentesco e a dimensão de complementaridade socioeconômica onde grupos familiares ou circunvizinhos ajudam outros grupos no deslocamento.

Nessa linha argumentativa, Alfonfo Hinojosa Gordonava aponta que na Bolívia, principalmente nas regiões de vales, a dimensão cultural desenhou que, desde o período pré-hispânico, diversos povos originários que residiam no altiplano e nos vales centrais "movimentaram uma cosmovisão espaço-cêntrica que se manifestava em sua permanente mobilidade e utilização de diferentes espaços geográficos e ecológicos, de tal maneira que as migrações foram uma invariável em suas práticas de sobrevivência e reprodução social" (2009, p.18. tradução minha). Essa perspectiva de análise traz alguns elementos que foram discutidos na dissertação de mestrado: uma visão particular dos narradores ao entrelaçarem seus deslocamentos a elementos culturais, e às vezes de cunho religioso. Assim, o sociólogo explicou em sua entrevista que

a migração boliviana é um problema estrutural da sociedade e de sua composição, por exemplo, não faz parte de um desenvolvimento recente, é um fator histórico antigo e que passou por vários momentos históricos, obedecendo diferentes dinâmicas. A maioria é migração laboral. As pessoas partem cedo, são trabalhadores adjacentes que seguem com destino a Espanha e aos Estados Unidos, vão sem titubear, e os outros países são destinos limítrofes, principalmente Argentina e Brasil, o Chile também foi uma escolha do passado, para onde foram muitos bolivianos. (Alfonso Hinosoja Gordonava, mais de 40 anos, residente de La Paz, na Bolívia, entrevista realizada em 4/10/2010, tradução minha).

As análises desenvolvidas por Alfonso Hinojosa Gordonava desconstroem as explicações que tentam vincular o processo migratório boliviano como sendo uma problemática recente, motivada, somente, por crises econômicas. O sociólogo estabelece que a migração boliviana é uma questão cultural, onde prevalece uma cosmovisão do espaço e do tempo manifestado no contínuo processo de deslocamento dos povos. De acordo com ele, o processo migratório obedece tal composição integrando as práticas de sobrevivência dos grupos, uma vez que o clima e a composição do espaço dos Andes influenciam o deslocamento em 
virtude das geadas, onde o ambiente produz ciclos naturais, os quais por sua vez, interferem no constante deslocamento de tais povos, principalmente de algumas regiões de Oruro, La Paz, Potosí. Atualmente, interpretações como estas voltaram a ser discutidas em virtude do aquecimento global, que provoca o degelo das montanhas interferindo no espaço desses povos, motivando as conhecidas migrações forçadas.

Esta dimensão histórico-cultural dos processos migratórios nacionais e particularmente cochabambinos faz-se necessário na medida em que fixamos nela uma determinada maneira de perceber e fazer os movimentos populacionais nestas altitudes. Em todo caso, não se trata simplesmente de estratégias de sobrevivência moderna, mas de um habitus, de uma prática associada a uma cosmovisão particular, de um saber de vida que pemitia e permite ainda uma melhor e mais sustentável utilização dos recursos naturais e não para a sobrevivência de uma família, mas para a vida e reprodução de toda uma comunidade e sociedade. (HINOJOSA GORDONAVA, Alfonso R. 2009, p.18, grifo do autor, tradução minha).

Para Hinojosa Gordonava (2009), atualmente a Bolívia é tida como um país em diáspora, devido ao crescimento da migração nesse país, e seu impacto dentro das fronteiras obrigam a considerar o caso boliviano como um dos mais significativos para o estudo da migração internacional no âmbito da América Latina. Uma das explicações possíveis está pautada na ideia de crise que o país vive no cenário atual.

Assim, percebemos que as linguagens, as imagens e as práticas aglutinadas para reinventar uma comunidade boliviana em São Paulo conduzem à conclusão de que "a história que se tornou parte do cabedal de conhecimento ou ideologia da nação, Estado ou movimento não corresponde ao que foi realmente conservado na memória popular, mas àquilo que foi selecionado, escrito, descrito, popularizado e institucionalizado por quem estava encarregado de fazê-lo" (HOBSBAWN, 1997, p.21). Com isto, notificamos que as reinvenções das tradições são construídas por meio de afetos sociais constituídos pelas comunidades dos bolivianos residentes em São Paulo.

Percebemos que reinventar uma Bolívia faz parte de uma estratégia social para que as pessoas se sintam pertencentes a uma comunidade afetiva, mesmo que essa seja apenas uma projeção idealizada no discurso. Partilhamos, assim, do conceito postulado pelo historiador Benedict Anderson que, em seu livro "Comunidades Imaginadas" (2008), diz que as nações são "imaginadas" no sentido de fazerem sentido para a "alma" e constituírem objetos de desejos e projeções porque possuem uma validade emocional densa. As nações são

imaginadas porque mesmo os membros da mais minúscula das nações jamais conhecerão, encontrarão, ou sequer ouvirão falar da maioria de seus companheiros, embora, todos tenham em mente a imagem viva da comunhão entre eles. [...] 'O nacionalismo não é o despertar das nações para a autoconsciência: ele inventa nações onde elas não existem'. [...] Imagina-se a nação ilimitada porque mesmo a maior delas, que agregue, digamos, um milhão de habitantes, possui fronteiras finitas, ainda que elásticas, para além das quais existem outras nações. [...] ela é imaginada porque, independentemente da desigualdade e da exploração efetivas que possam existir dentro dela, a nação sempre é concebida como uma profunda camaradagem horizontal. No fundo, foi essa fraternidade que tornou possível, nestes últimos séculos, tantos milhões de pessoas tenham-se não tanto a matar, mas sobretudo a morrer por essas criações imaginárias limitadas (2008, p.34, grifo do autor).

É precisamente para não cair no tempo vazio e homogêneo de um passado longínquo que muitos narradores atrelaram suas memórias, recriadas em um presente, a uma comunidade imaginada, pois mesmo desconhecendo a multiplicidade das vozes dos seus outros patrícios, projetam a ideia de comunidade por meio de ritos culturais. Por estarem atrelados a uma memória afetiva amalgamadas em seus símbolos cívicos e religiosos, são possíveis recriações de uma Bolívia mítica, sempre ressignificada na metrópole de São Paulo.

\section{Referências bibliográficas}

ANDERSON, Benedict. Comunidades Imaginadas: reflexões sobre a origem e difusão do nacionalismo. São Paulo: Companhia das Letras, 2008. 
Artigos

ALBÓ, Xavier; Sandoval, Godofredo; Greves. Chuquiyawu: La cara aymara de La Paz. La Paz: CIPCA, 1982.

CHIRINO, Fabiana; JÁUREGUI, Maggie; JORDÁN, Nelson; HOLLWEG, Karin. Huellas Migratorias: duelo y religión em las familias de migrantes del Plan Tres Mil de la ciudad de Santa Cruz. Santa Cruz: Fundación PIEB, 2009.

HALL, Stuart. Da Diáspora: identidades e mediações culturais. Belo Horizonte: Ed. UFMG, 2006.

Quem precisa da identidade? In: Identidade e Diferença: a perspectiva dos estudos culturais. (Org.) SILVA, Tomaz Tadeu da. Woodward, Kathryn. Rio de Janeiro: Vozes, 2000.

A identidade cultural na pós-modernidade. Rio de Janeiro: DP\&A, 2003.

HINOJOSA GORDONAVA, Alfonso R. Buscando la Vida: familias bolivianas transnacionales en España. La Paz: CLACSO: Fundación PIEB, 2009.

Migración Transnacional y sus efectos en Bolivia. Las Paz: Fundación PIEB, 2009.

HOBSBAWN, Eric; RANGER, Terence (Org.) A Invenção das Tradições. Rio de Janeiro: Paz e Terra, 1997.

HOLANDA, Fabíola; MEIHY, José Carlos Sebe Bom. História Oral: como fazer como pensar. São Paulo: Contexto, 2007.

LESSER, Jeffrey. A negociação da Identidade Nacional: imigrantes, minorias e a luta pela etnicidade no Brasil. São Paulo: Editora Unesp, 2001.

LEVIT'T, Peggy; GLICK, Nina Schiller. Perspectivas internacionales sobre migración: conceptualizar la simultaneidad. In: Migración y Desarrollo. 2004

MEIHY, José Carlos Sebe Bom. Brasil fora de si: experiências de brasileiros em Nova York. São Paulo: Parábola Editorial, 2004.

Manual de História oral. 5 ed., São Paulo: Loyola, 2005.

Palavras aos jovens oralistas: entrevistas em história oral. Oralidades: Revista de História Oral, São Paulo, Ano I, n. 03, jan./jun. 2008, p. 141-150.

Mas há fronteiras? Migrações internacionais: desafios para o século XXI. São Paulo: Memorial do Imigrante, p.31-50.

PAES, Vanessa Generoso. Trânsito de Identidades e Estratégias de Negociação Familiar: deslocamentos populacionais entre a Bolívia e o Brasil. Dissertação (Mestrado em História Social) - Faculdade de Filosofia, Letras e Ciências Humanas, Universidade de Universidade de São Paulo, São Paulo, 2011.

SAYAD, Abdelmalek. A Imigração ou os Paradoxos da Alteridade. SP: EDUSP, 1998.

THOMSON, Alistair. Histórias (co) movedoras: História oral e estudos de migração. In Rev. Bras. Hist., 2002, vol.22, no.44, p.341-364. ISSN 0102-0188.

ZAMBERLAM, Jurandir. O processo migratório no Brasil e os desafios da mobilidade humana na globalizarão. Porto Alegre: Pallotti, 2004. 